\title{
CAN SUBSIDIARIES OF FOREIGN BANKS CONTRIBUTE TO THE STABILITY OF THE FOREX MARKET IN EMERGING ECONOMIES? A LOOK AT SOME EVIDENCE FROM THE MEXICAN FINANCIAL SYSTEM
}

\author{
Alejandro Reynoso \\ Working Paper 8864 \\ http://www.nber.org/papers/w8864 \\ NATIONAL BUREAU OF ECONOMIC RESEARCH \\ 1050 Massachusetts Avenue \\ Cambridge, MA 02138 \\ April 2002
}

The views expressed herein are those of the author and not necessarily those of the National Bureau of Economic Research.

(C) 2002 by Alejandro Reynoso. All rights reserved. Short sections of text, not to exceed two paragraphs, may be quoted without explicit permission provided that full credit, including (C) notice, is given to the source. 
Can Subsidiaries of Foreign Banks Contribute to the Stability of the Forex Market in Emerging Economies? A Look at Some Evidence from the Mexican Financial System Alejandro Reynoso NBER Working Paper No. 8864

April 2002

JEL No. E58, F31

\begin{abstract}
Over the last decade, the ownership of the banking sector in Latin America has changed hands from local shareholders to large foreign banks from Spain and the United States. It is also a fact that the foreign exchange market in these countries has been segmented through various kinds of restrictions, because the central bank is unable to function as a lender of last resort in a currency other than its own. The standing issue is whether in practice, a parent bank effectively takes the role of such lender of last resort in supporting its subsidiaries overseas. If that were to be the case, the question is if having a significant participation of foreign subsidiaries is a necessary condition for lifting such restrictions. The data on the compliance of domestic and foreign banks with the dollar reserve requirements in Mexico is used to try to address this question. The answer is a qualified yes. When there are weak domestic banks, it seems that subsidiaries of foreign banks have a better access to funding in foreign exchange, specially in times of stress. However, when compared with strong domestic banks, the evidence suggests that these local entities can do as well or even better than the foreign subsidiaries.
\end{abstract}

\footnotetext{
Alejandro Reynoso

Faculty Visitor

NBER

1050 Massachusetts Ave.

Office 207

Cambridge, MA 02138

areynoso@nber.org
} 


\section{Introduction}

The financial markets in most countries of Latin America, perhaps with the exception of Brazil, Uruguay and Panama, share two distinctive features. On the one hand, over the last decade the ownership of the banking sector has changed hands from local shareholders to large foreign banks, mostly from Spain and the United States. On the other hand, their foreign exchange market remain segmented to the extent that there are still various forms of exchange controls, ranging from dual markets to restrictions to borrowing or lending in foreign currencies ${ }^{1}$

The alluded restrictions are not necessarily the outcome of the policy objective of fixing an exchange rate at a given level. The truth is, that there are countries like Chile or Mexico, where in spite of a de facto flexibility of their currencies, they have kept some restrictions on either capital outflows or on the foreign currency composition of the balance sheet of commercial banks.

In this paper we focus on the case where the segmentation of the foreign exchange market is a consequence of the fact that that the Central Bank can not function as a lender of last resort in a currency other than its own. The standing issue is whether, in times of stress, the parent bank effectively takes the role of such lender of last resort in supporting its subsidiaries overseas.

The scenario that we have in mind would be one where the host economy suffers a shock that adversely affects its access to foreign financing. In such a situation, it may be the case that the local banks would find it very costly or even impossible to renew their outstanding short term credit lines, having to rely on whatever support they may get from the local authorities. It may also happen that the foreign subsidiaries would recur to their parent bank for supplementary funding at pre-shock rates.

If this were the case, a country with a significant participation of foreign banks in its economy, could afford to lift most restrictions on foreign exchange transactions without incurring in significant risks. This also raises the question of whether having a significant participation of foreign subsidiaries should be thought as a necessary condition for lifting such restrictions.

This paper follows two previous ones on the issue of regulation of foreign exchange transactions that focus on the Mexican banking sector (Reynoso

\footnotetext{
${ }^{1}$ See Abrams and Beato [1] for a rather comprehensive list of examples in Latin America and elsewhere.
} 
[6] and [7]). They explain to some detail, why and how banks are required to hold a certain minimum amount of liquid assets, denominated in foreign exchange and issued by $A 1-P 1$ rated governments or corporations. This paper also joins others, like Chinn and Dooley [2] and Gultekin and Penati [4], who look at different sets of data to try to assess the impacto of different kinds of forex market segmentation.

Here, we suggest that the setting of Mexico's regulation, specially during a period covering from December of 1997 to November of 1999, offers a rather practical way of looking at the response of domestic banks vis à vis that of subsidiaries of foreign banks in times of stress:

- During the time, the Russian, Southeast Asian and Brazilian crises had an appreciable effect on the overall cost of funding for bearers of Mexico risk.

- The available information allows to distinguish the performance of the dollar book of domestic banks and foreign subsidiaries in Mexico. It is possible to see how institutions comply with the statutory requirement and to measure the excess reserves on a daily basis.

- At the time, Mexico still had a substantial proportion of the banking sector assets in the hands of Mexican banks while some large foreign banks, like Citibank or Santander, were already present. ${ }^{2}$

This paper has four sections. In the first one we present a simple model of the optimal response of a commercial bank to a reserve requirement, like the one in place in Mexico. Section two dwells on the observable characteristics of the model that are relevant for its estimation and testing. Section three presents the data and the model to be estimated. Section four has the estimations and test results.

\section{A simple testable model}

\subsection{Optimal excess reserves}

Consider an economy where the regulation of the banking system distinguishes between domestic currency and foreign currency transactions. For

\footnotetext{
${ }^{2}$ In contrast, today more than $80 \%$ of such assets are managed by foreign subsidiaries.
} 
notational purposes we will refer to the domestic currency as pesos. The foreign currency will be the dollar. In this setting, the authorities require banks to carry two books: one for peso denominated transactions; the other one for dollar operations.

Banks may or may not be required to hold liquid reserves for their peso book. However, they are required to hold a certain proportion of their total dollar liabilities in the form of liquid assets.

We will assume that all banks can fund their dollar holdings in the interbank market or by issuing tradeable certificates of deposit placed abroad. This implies that the general public is not allowed to maintain dollar deposits in the domestic financial sector.

We will also assume that there is a subset of banks, the foreign banks, which can also get their funding from their parent abroad.

We will look now at the decision of the domestic banks on what should be an adequate level of excess reserves in foreign exchange. Lets $A$ be such excess. We will assume that $A$ behaves like equation (1) with $z \sim \mathrm{N}(0,1)$.

$$
A=\mu+\sigma z
$$

Now, lets define a variable $\Lambda$, which is the cost that banks bear from carrying the excess reserves. This cost has two components: when a bank complies with the regulation, it pays $\theta$, which is the difference between the funding rate and the return on very low yield short term instruments. If the bank does not comply with the regulation, it is fined by the authorities, to whom it has to pay a penalty rate $\Theta$.

$$
\begin{aligned}
\Lambda & =-\Theta \int_{-\infty}^{0} f(A, \mu, \sigma) d A+\theta \int_{0}^{\infty} f(A, \mu, \sigma) d A \\
f(A, \mu, \sigma) & =\frac{1}{\sigma \sqrt{2 \pi}} \exp -\frac{(A-\mu)^{2}}{2 \sigma^{2}}
\end{aligned}
$$

Let $\mu$ be the control variable used by banks in trying to minimize $\Lambda$ as described by equation (2). Take figure (1)as a visualization aid that displays how much the cost, $\Lambda$ would be for various choices of $\mu$ when $\Theta=0.20$, $\theta=0.10$ and $\sigma=1$.

Figure (2) results from the solution of the minimization problem. The surface is the optimal average excess reserves, $\mu^{*}$, for various combinations of values of $\Theta$ and $\sigma$. 


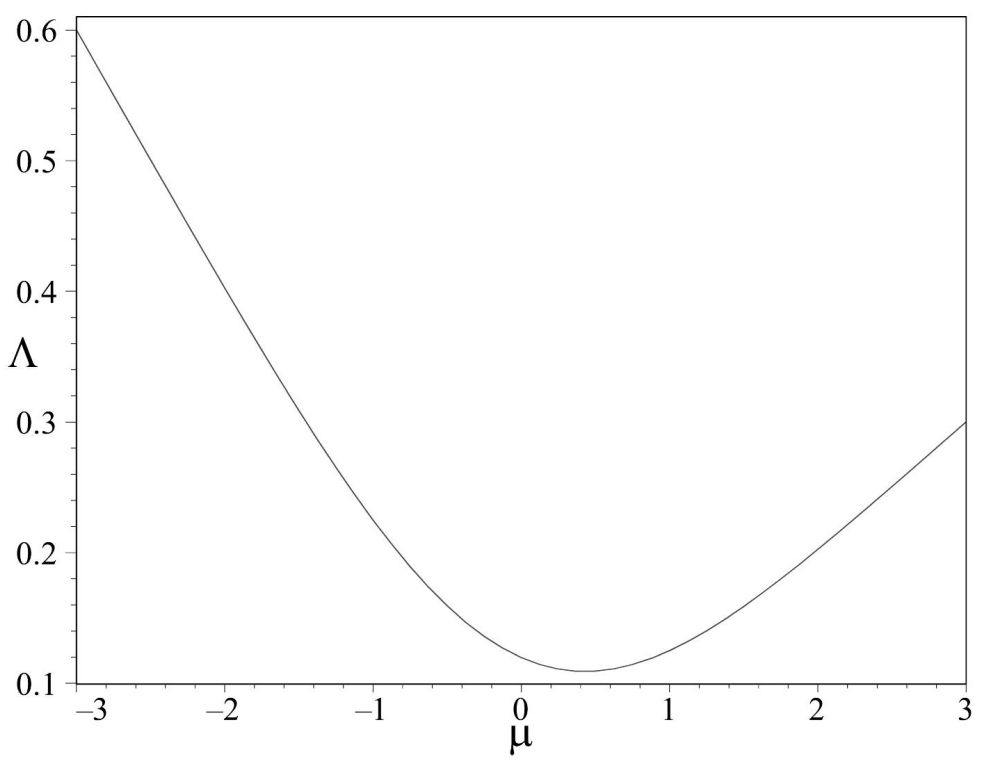

Figure 1: Cost function. $\Theta=0.20, \theta=0.10$ and $\sigma=1$

\subsection{Testable features}

Two salient facts are worth noticing from the solution above:

- As the penalty rate, $\Theta$, gets closer to the market funding rate $\theta, \mu^{*}$ gets closer to zero. Therefore, if foreign banks can get funding from their headquarters at rates below the penalty rate, then they would show, in average, lower levels of excess reserves than the local banks, who by assumption cannot avoid the penalty whenever they get hit by a large enough shock $\left(z \leq \frac{-\mu}{\sigma}\right)$

- The average excess reserves increases with the volatility of the funding needs. Therefore, in times of stress, one should expect to see an increase in the average holdings of reserves across banks. Only in the extreme case where $\Theta=\theta$, changes in volatility would have no impact on $\mu^{*}$ 


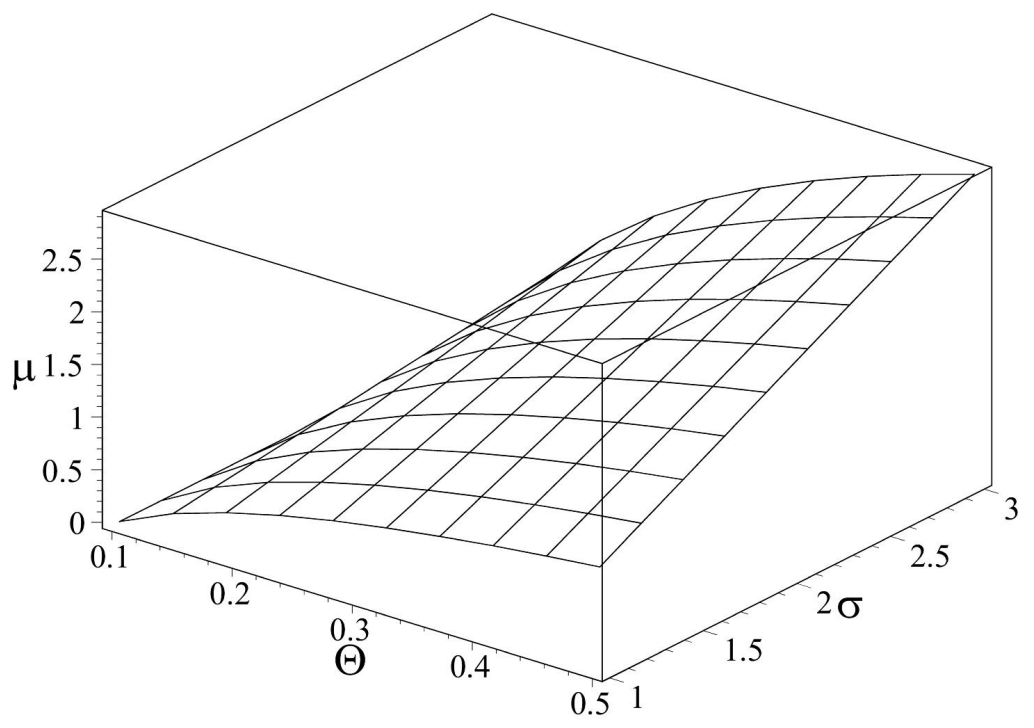

Figure 2: Optimal Average Excess Reserves $\mu^{*}$ for $\theta=0.10$

\section{Observable characteristics of the model rel- evant for its estimation and testing.}

Following the reasoning above, our objective would be to test whether, caeteris paribus, the subsidiaries of foreign banks show significantly lower levels of excess reserves than the domestic banks.

\subsection{Censored observations}

Notice that, regardless of their ownership status, those banks complying with the reserve requirement would be expected to record a level of excess reserves described by equation (4)

$$
A_{t}= \begin{cases}\mu^{*}+\sigma z_{t} & z_{t} \geq \frac{-\mu^{*}}{\sigma} \\ 0 & \text { otherwise }\end{cases}
$$

From this specification, the sample mean of the excess reserves defined by (5) will overestimate $\mu^{*}$, specially for those banks with unlimited access to external funding. 

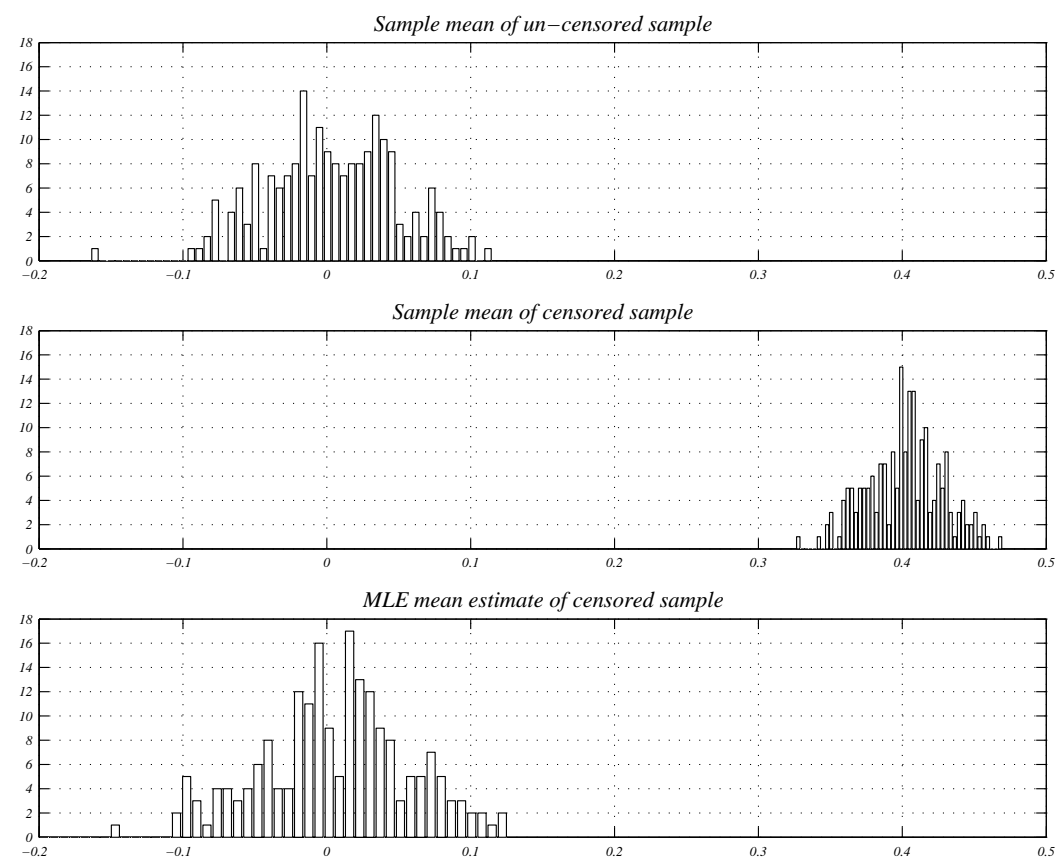

Figure 3: Histograms for various estimates of $\mu$

$$
\hat{\mu}=\frac{1}{N-1} \sum_{t=1}^{N} A_{t}
$$

Figure 3 displays an example of this bias. The first panel shows the histogram for the sample means of 200 samples, each one with 500 independent observations generated by the process (1), with $\mu^{*}=0$ and $z_{t} \sim \mathrm{N}(0,1)$ for all t.

The second panel shows the distribution of the same statistic $\hat{\mu}$ for the process (4). The statistic is noticeably biased upwards with a mean around 0.4 .

The third panel depicts the distribution of $\mu^{M L E}$, which expression (6), where $f$ is defined by equation (3) above. In this case the estimator is once again unbiased.

$$
L=\sum_{t, A_{t}>0} \log \left(f\left(A_{t}, \mu, 1\right)\right)+\sum_{t, A_{t} \leq 0} \log (f(0, \mu, 1))
$$




\subsection{The issue of smooth pasting}

In practice, most compliant banks will not show excess reserve values of exactly zero. It is reasonable to think that even the bank with the best access to credit will show some positive level for $A_{t}$, instead of hitting the boundary every time $z_{t}$ is negative enough . This is like a smooth pasting condition.

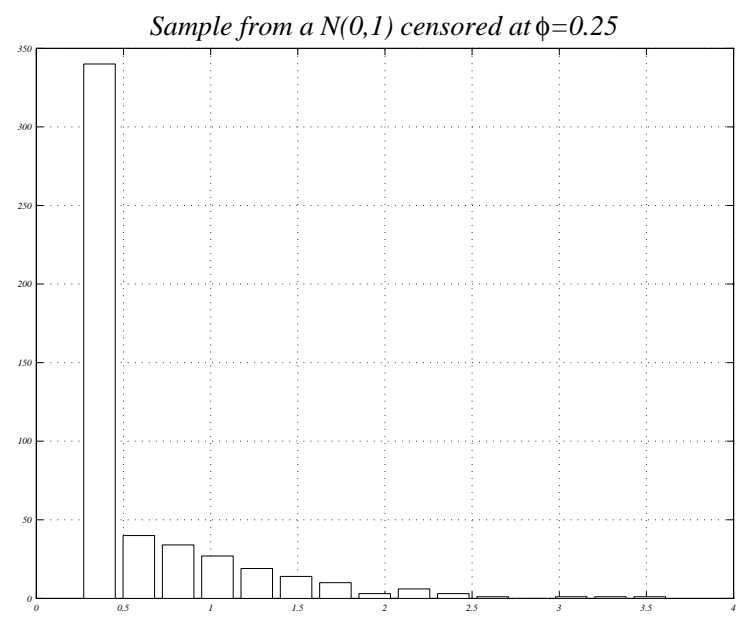

Figure 4: Smooth pasting. Histogram from a sample of 500 observations

To see what this implies, lets consider that instead of having equation (4), banks follow rule (7), with $\phi$ very small, but larger than 0. One example of a histogram of excess reserves resulting from this rule is given by figure (4).

$$
A_{t}= \begin{cases}\mu^{*}+\sigma z_{t} & z_{t} \geq \frac{\phi-\mu^{*}}{\sigma} \\ \phi & \text { otherwise }\end{cases}
$$

In a case like this, the solution to the maximum likelihood estimation problem of equation (6) would be (8). This is because the value for which we would be making the censoring lies behind the actual point where our hypothetical bank decided to set its minimum excess reserves. From an estimation standpoint, this result will show the same bias as the one illustrated in the second panel of figure 3.

$$
\mu^{M L E}=\frac{1}{N} \sum_{t=1}^{N} A_{t}
$$


One possible solution would be to arbitrarily censor the observations at some level above zero. This in turns, raises the question on where to censor the data.

Figure (5) reports the histogram of the estimator $\mu^{\prime M L E}$, which maximizes equation (9), with $A_{t}$ generated by a process (4), and for various values of $\phi$. The number of simulations is the same as in the previous example.

$$
L^{\prime}=\sum_{t, A_{t}>\phi} \log \left(f\left(A_{t}, \mu, 1\right)\right)+\sum_{t, A_{t} \leq \phi} \log (f(\phi, \mu, 1))
$$
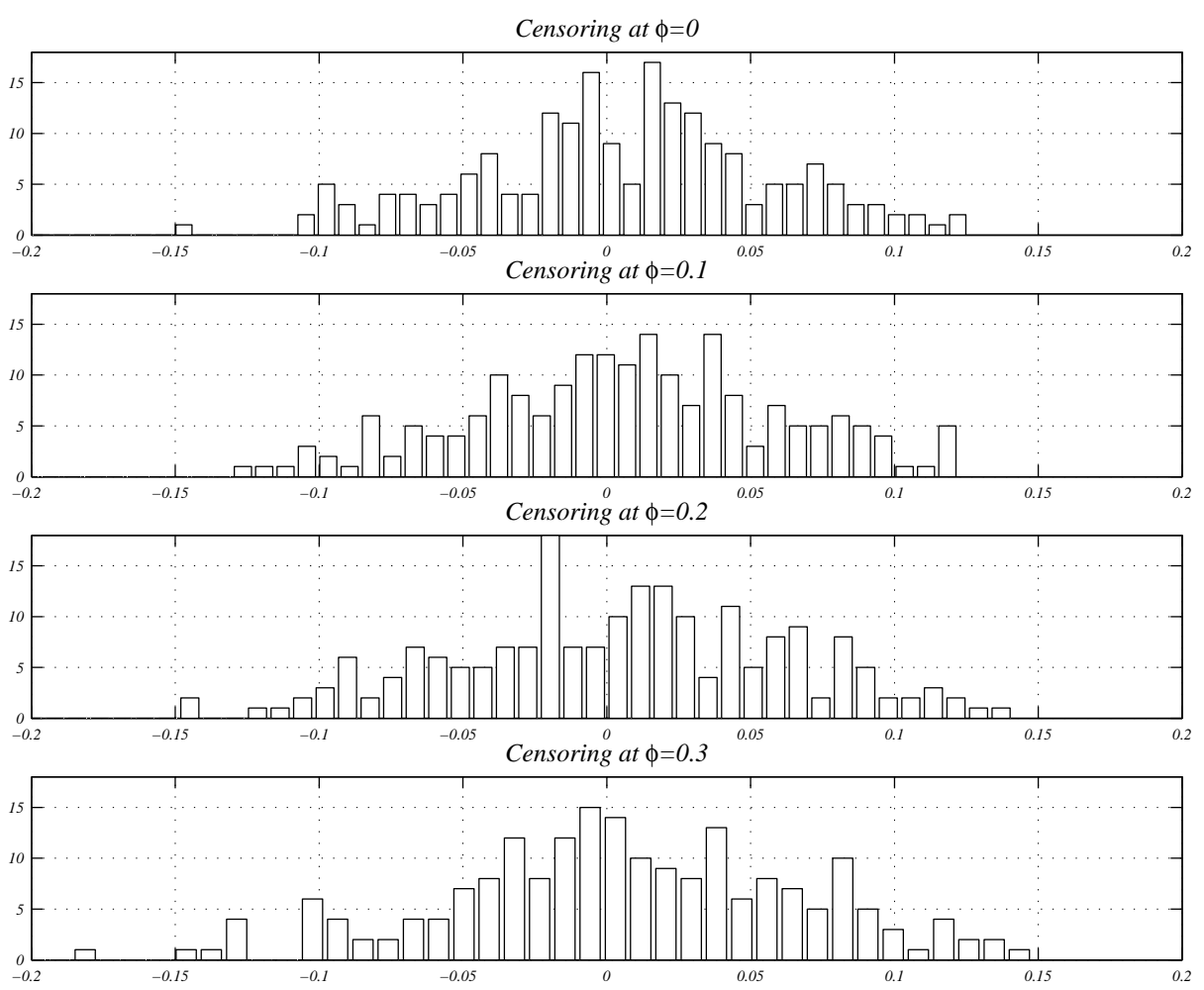

Figure 5: Histograms of $\mu^{\prime M L E}$ for varios values of $\phi$

Three remarks follow from this exercise.

- Changing the point of arbitrary censoring does not induce any bias in the estimator.

- As the point of arbitrary censoring $\phi$ gets farther away from the actual mean the distribution of the estimator shows a larger variance. 
- This very situation is a consequence of a likelihood function which gets flatter with larger values of $\phi$, which not only has the consequence of less precise estimations but, depending on the algorithm used, it also makes the numerical optimization process slower and, sometimes, unable to find a solution.

\subsection{Implementation Steps}

In sections 3 and 4 we will define and estimate a model for testing whether or not banks have differential access to foreign funding depending on who owns them.

In doing so, and for the reasons highlighted above, we will proceed along the following three steps:

- Building a panel data set that would allow us to compare the trajectories of excess reserves across banks during a period where credit to Emerging Markets was tight.

- Further censoring the available data on excess reserves to address the smooth pasting issue.

- Estimating the model along the lines of the TOBIT methodology.

\section{Model Specification}

\subsection{The Data}

As we mentioned before, between December of 1997 and December of 1999, the Emerging markets went through the Asian, Russian and Brazilian crisis. During these episodes, the access of Emerging Economies to the international credit markets may have not stopped altogether, but it definitely got significantly tighter. Even in the more fortunate cases, like Chile, where a decoupling from other economies crisis was claimed, the spreads of their sovereign and corporate debt increased appreciably.

The commercial banks in Mexico were definitely affected by this situation. Although there is not a comprehensive and publicly available data on the conditions in which they got their financing, there is a good deal of anecdotal 


\begin{tabular}{|c|c|c|}
\hline Variable & Description & Source \\
\hline$A_{i, t}$ & $\begin{array}{l}\text { Excess reserves/30 moving average } \\
\text { of liabilities due on the next day } \\
\text { Periodicity: Daily } 12 / 01 / 9712 / 01 / 99 \\
\text { Number of banks: } 19\end{array}$ & Hernandez [5] \\
\hline$M E X I C A N_{i}$ & $\begin{array}{l}\text { Dummy variable } \\
\text { Value: } 1 \text { if bank is Mexican }\end{array}$ & Hernandez [5] \\
\hline$A M E R I C A N_{i}$ & $\begin{array}{l}\text { Dummy Variable } \\
\text { Value: } 1 \text { if holding is US corporation. }\end{array}$ & Hernandez [5] \\
\hline$D E R I V A T I V E S_{i}$ & $\begin{array}{l}\text { Dummy variable } \\
\text { Value: } 1 \text { if bank complies with the } \\
\text { risk management standards that the } \\
\text { central bank requires from } \\
\text { intermediaries to operate with derivatives. }\end{array}$ & Hernandez [5] \\
\hline$S P R E A D_{t}$ & $\begin{array}{l}\text { Bid ask spread in the dollar-peso market } \\
\text { Periodicity: Daily 12/01/97 12/01/99 } \\
\text { Dollar venta - Dollar compra } \\
\text { Units: (MEP/US\$) }\end{array}$ & Infosel Financiero \\
\hline$C E T E S_{t}$ & $\begin{array}{l}\text { One day repo rate for } 28 \text { day } \\
\text { Mexican Treasury bills, CETES } \\
\text { Periodicity: Daily } 12 / 01 / 9712 / 01 / 99 \\
\text { Units: percent }\end{array}$ & Infosel Financiero \\
\hline$U M S_{t}$ & $\begin{array}{l}\text { Spread over US Treasuries of the } \\
\text { UMS } 11 \frac{1}{2} \text { due in } 2026 \\
\text { Periodicity: Daily } 12 / 01 / 9712 / 01 / 99 \\
\text { Units: basis points }\end{array}$ & JP Morgan \\
\hline
\end{tabular}

Table 1: Characteristics of the Data

evidence which suggests that they had to come up with rather creative ways of building an acceptable collateral to keep the short-term debt rolling over. ${ }^{3}$

At the time, there were 19 commercial banks in Mexico which:

- Were neither intervened by the authorities nor were in the process of liquidation, as a consequence of the 1994-95 crisis.

- Were active participants in the foreign exchange market.

${ }^{3}$ One of the best examples is the securitization of credit card receivables for transactions in dollars. Also, the securitization of receivables from money transfers made by expatriated Mexican workers in the US 
All those banks were subject to regulation $2019 / 95^{4}$, which basically required them to maintain a certain minimum balance in short term US Treasuries or equivalent in $A 1 / P 1$-rated dollar denominated debt instruments.

Banks were asked to meet this requirement on a daily basis. To that end, they filled out a report known as $R L 004{ }^{5}$, which shows information on the term structure of their assets and liabilities in dollars.

In principle, the information from the $R L 004$ is considered as confidential by the central bank. Fortunately, there is a study by Hernandez [5] who focuses on the degree of compliance of the banks during our sample period. The study contains disaggregated information in such a way that it is possible to distinguish across banks although, it is not possible to exactly associate the data to any specific bank. The main reason is that in order to maintain the confidentiality, Hernandez reports the data after it is normalized by a 30 day centered moving average of the total liabilities due on the next business day.

The data used in this paper is described in table 1. The sample has two years of daily data for 19 banks. These banks are classified according to two criteria:

Nationality of the owner. We will recognize three categories, Mexican, banks with American or Canadian parents, and the rest: European and Asian. We will use two dummy variables to capture the effects of this classification: one for the Mexican and another for the Americans. The constant term will therefore capture the fixed effects of the other nationalities. the regressions

Strength of internal controls. Regulation 2019/95 also stated that only banks with adequate risk management capabilities could operate with dollar-derivatives. The central bank also precluded banks with inadequate capitalization from participating in the derivatives markets. That was the case of banks who substantially benefited from the regulatory forbearance granted by the National Banking Commission. ${ }^{6}$ In some

\footnotetext{
${ }^{4}$ Described in more detail by Hernandez [5] and by Reynoso [6]

${ }^{5}$ Later on it was replaced by the ALCME report, currently in use

${ }^{6}$ It must be noticed that in Mexico, banking regulation is shared by the Ministry of Finance (through the National Banking Commission) and the autonomous Central Bank. Their policy approach does not necessarily coincides at all times. That is the reason why one could see some facilities granted by some authority which are not acknowledged by the other.
} 
way, this dummy variable can also be thought as a proxy of the underlying financial strength of the institution. ${ }^{7}$

Some macro variables will also be used to reflect the general market conditions, such as the spread in the peso-dollar market; the one day repo rate for the 28 day CETE (Treasury Note) and the strip spread of the UMS $11 \frac{1}{2} \%$ due in 2026 over the comparable US Treasury instrument.

\subsection{The model}

The basic idea is that all banks look every day at the macro environment and determines a reasonable amount of excess reserves. In principle, all banks would process the macro information in the same way. Once this is done, each bank may or may not include an additional amount of reserves. This will depend on how skilled they are to handle risk and how certain they are about having a reliable source of funding in times of stress. Equation(10) tries to describe this behavior.

$$
\begin{aligned}
A_{i, t}= & \text { constant }+\beta_{1} A_{i, t-1}+ \\
& \beta_{2} \text { MEXICAN } N_{i}+\beta_{3} A M E R I C A N_{i}+ \\
& \beta_{4} \text { SPREADt }+\beta_{5} U M S+\beta_{6} C E T E S \\
& \beta_{7} \text { DERIVATIVES } S_{i}+ \\
& \epsilon_{i, t} \\
& \mathrm{t}=\{1, \ldots, 507\} \text { and } \mathrm{i}=\{1, \ldots, 19\}
\end{aligned}
$$

Our main purpose will be to compare the situation of a group of banks relative to the others. For that reason we will focus on the relative value of the estimates of the constant term, $\beta_{2}$ and $\beta_{3}$. In principle, these parameters give us a ranking of banks from the point of view of their access to funding. Those with smaller $\beta$ will be thought as the ones with a better access to the credit market. Table 2 displays the cases that we will be looking at in the next section.

\footnotetext{
${ }^{7}$ It should be said that the published information on the capital adequacy of banks is not used here for, in our opinion, such data was excessively contaminated by the accounting facilities granted by the authorities at the time.
} 


\begin{tabular}{|c|c|}
\hline Case & Interpretation \\
\hline constant $=\beta_{2}=\beta_{3}$ & $\begin{array}{l}\text { No evidence of differential access to } \\
\text { funding by reason of the nationality } \\
\text { of the controlling shareholder }\end{array}$ \\
\hline$\beta_{2}>0$ & $\begin{array}{l}\text { Evidence of a more } \\
\text { advantageous access of European-Asian } \\
\text { banks versus Mexican banks }\end{array}$ \\
\hline$\beta_{3}>0$ & $\begin{array}{l}\text { Evidence of a more } \\
\text { advantageous access of European-Asian } \\
\text { banks versus American banks }\end{array}$ \\
\hline$\beta_{2}-\beta_{3}>0$ & $\begin{array}{l}\text { Evidence of a more } \\
\text { advantageous access of American } \\
\text { banks versus Mexican banks }\end{array}$ \\
\hline
\end{tabular}

Table 2: Interpretation of the parameters

\section{Estimation}

\subsection{A point of Reference: FGLS estimation}

Without overlooking the discussion of section 2, we present here the results of the FGLS estimation of the model in equation(10) as a way of having a point of reference to compare the results of the TOBIT estimation ahead.

Table 3 displays the results of a simple panel data estimation under different assumptions about the structure of the variance-covariance matrix of $\epsilon_{i, t}$.

The first column corresponds to a pooled OLS estimation where the variance of the error term is described by equation (11).

$$
E\left(\epsilon_{i, t} \epsilon_{i^{\prime}, t^{\prime}}\right)= \begin{cases}\sigma^{2} & t=t^{\prime} \text { and } i=i^{\prime} \\ 0 & \text { otherwise }\end{cases}
$$

The second column assumes that each panel is homoscedastic, although there may be differences across blocks.

$$
E\left(\epsilon_{i, t} \quad \epsilon_{i^{\prime}, t^{\prime}}\right)= \begin{cases}\sigma_{i}^{2} & i=i^{\prime}, t=t^{\prime} \\ & \sigma_{i}^{2} \neq \sigma_{i^{\prime}}^{2}, i \neq i^{\prime} \\ 0 & \text { otherwise }\end{cases}
$$

The third column considers the possibility of autocorrelation with the structure described by expression (13). 


$$
E\left(\epsilon_{i, t} \epsilon_{i^{\prime}, t^{\prime}}\right)= \begin{cases}\sigma_{i}^{2} & i=i^{\prime}, t=t^{\prime} \\ \rho_{i} \sigma_{i}^{2} & i=i^{\prime}, t^{\prime}=t-1 \\ & \sigma_{i}^{2} \neq \sigma_{i^{\prime}}^{2}, i \neq i^{\prime} \\ & \rho_{i} \neq \rho_{i^{\prime}}, i \neq i^{\prime} \\ 0 & \text { otherwise }\end{cases}
$$

In our opinion, the remarks worth making from these results are:

- The specification that appears to be more adequate is the one described in equation (12), which is the case where we have heteroscedasticity but no autocorrelation. To see this, we could perform a nested sequence of log-likelihood ratio tests $(\lambda)^{8}$. We compare first the case of autocorrelation and heteroscedasticity versus the heteroscedasticity case. Here the statistic $\lambda$ is negative, which implies a $p$-value (1 degree of freedom) of 1.000. Now, the second test, of heteroscedasticity versus homoscedasticity reports a p-value (19 degrees of freedom) of 0.000, which suggests that we can stop the nested testing here.

- While the constant term appears to be significantly different from zero, the dummies for Mexican and American banks are not significantly different from zero. For completeness, table 4 reports the $\chi^{2}$ test for the null hypothesis of $\beta_{2}=\beta_{3}$, not being able to reject it at any reasonable level of significance.

- Following Bonferroni's criterion for 5\% significance level testing, the critical p-values should be around $0.064 \%$ for our 8 coefficient model 9 . This leaves only the constant term, the coefficient on the lagged variable and the DERIVATIVES dummy as significant. Furthermore, the DERIVATIVES dummy has similar size and opposite sign as the constant. This would lead to the conclusion that it is not the nationality of the bank what matters, but its financial and organizational strength. Therefore, in the case of a bank with a DERIVATIVES dummy equal

${ }^{8}$ See Greene [3], sections 11.3 and 11.4. It is established there that $\lambda=L_{c}-L_{u c}$, with $L_{c}$ being the log-likelihood evaluated at the estimated parameters in the constrained exercise, and $L_{u c}$ the corresponding for the constrained one. This statistic has a $\chi^{2}$ distribution with $f$ degrees of freedom, being these the number of parametric restrictions imposed

${ }^{9}$ For simultaneous testing, the probability of rejecting at least one of $q$ hypothesis is $P(\alpha, q)=1-(1-\alpha)^{q}$ 


\begin{tabular}{|c|c|c|c|}
\hline Coefficient & $\begin{array}{r}\text { Homoscedastic } \\
\text { no autocorrelation }\end{array}$ & $\begin{array}{r}\text { Heteroskedastic } \\
\text { no autocorrelation }\end{array}$ & $\begin{array}{r}\text { Heteroskedastic } \\
\text { autocorrelation }\end{array}$ \\
\hline$\beta_{1}$ & 0.7807 & 0.7970 & 0.6900 \\
\hline s.e. & 0.0063 & 0.0065 & 0.0079 \\
\hline$p$-value & 0.0000 & 0.0000 & 0.0000 \\
\hline$\beta_{2}$ & 0.1073 & 0.0084 & 0.0159 \\
\hline s.e. & 0.0306 & 0.0073 & 0.0101 \\
\hline$p$-value & 0.0005 & 0.2503 & 0.1162 \\
\hline$\beta_{3}$ & 0.0687 & 0.0061 & 0.0116 \\
\hline s.e. & 0.0371 & 0.0067 & 0.0093 \\
\hline$p$-value & 0.0644 & 0.3599 & 0.2085 \\
\hline$\beta_{4}$ & -1.0458 & -0.2277 & -0.2803 \\
\hline s.e. & 2.3953 & 0.5472 & 0.6614 \\
\hline p-value & 0.6624 & 0.6774 & 0.6718 \\
\hline$\beta_{5}$ & 0.0980 & 0.0092 & 0.0128 \\
\hline s.e. & 0.0283 & 0.0064 & 0.0086 \\
\hline$p$-value & 0.0005 & 0.1555 & 0.1374 \\
\hline$\beta_{6}$ & -0.0229 & -0.0017 & -0.0025 \\
\hline s.e. & 0.0048 & 0.0011 & 0.0015 \\
\hline$p$-value & 0.0000 & 0.1286 & 0.0874 \\
\hline$\beta_{7}$ & -0.1432 & -0.3004 & -0.4575 \\
\hline s.e. & 0.0307 & 0.0293 & 0.0369 \\
\hline$p$-value & 0.0000 & 0.0000 & 0.0000 \\
\hline constant & 0.2991 & 0.3063 & 0.4726 \\
\hline s.e. & 0.0670 & 0.0326 & 0.0415 \\
\hline$p$-value & 0.0000 & 0.0000 & 0.0000 \\
\hline $\mathrm{N}$ & 9632 & 9632 & 9632 \\
\hline \# coefficients & 8 & 8 & 8 \\
\hline \# covariances & 1 & 19 & 19 \\
\hline \# autocorr. & 0 & 0 & 1 \\
\hline Log-likelihood & -15643.0 & -7702.9 & -8198.9 \\
\hline$\chi^{2}$ & 16592.4 & 18277.6 & 9602.6 \\
\hline
\end{tabular}

Table 3: FGLS Estimation results. No banks excluded

\begin{tabular}{|l|r|r|r|}
\hline Coefficient & $\begin{array}{r}\text { Homoscedastic } \\
\text { no autocorrelation }\end{array}$ & $\begin{array}{r}\text { Heteroskedastic } \\
\text { no autocorrelation }\end{array}$ & $\begin{array}{r}\text { Heteroskedastic } \\
\text { autocorrelation }\end{array}$ \\
\hline$\widehat{\chi^{2}}$ & 1.2512 & 0.0963 & 0.1586 \\
$\operatorname{Pr}\left(\chi^{2}\right)>\widehat{\chi^{2}}$ & 0.2633 & 0.7564 & 0.6905 \\
\hline
\end{tabular}

Table 4: FGLS Testing $\beta_{2}=\beta_{3}$. No banks excluded 


\begin{tabular}{|c|c|c|c|}
\hline Bank & $\begin{array}{c}\text { \% of days } \\
\text { at fault }\end{array}$ & Bank & $\begin{array}{c}\text { \% of days } \\
\text { at fault }\end{array}$ \\
\hline 1 & 3.1 & 11 & 0.3 \\
2 & 0.0 & 12 & 1.1 \\
3 & 0.7 & 13 & 3.5 \\
4 & 0.4 & 14 & 0.0 \\
5 & 2.3 & 15 & 0.5 \\
6 & 0.0 & 16 & 11.32 \\
7 & 2.2 & 17 & 2.3 \\
9 & 0.7 & 19 & 0.2 \\
10 & 0.4 & & \\
& & & \\
\hline
\end{tabular}

Table 5: Compliance with the 2019/95 rule by bank

to one, its steady-state excess reserves will be very close to zero in expected value.

- Although too close to zero for an acceptable level of significance, the CETES and UMS coefficients show the sign we would have expected. On the one hand, the spread on the UMS increases with a tight dollar credit market. In such conditions, prudent banks would respond by increasing their holdings. On the other hand, the CETES rate is highly correlated with the interbank peso market, with which some banks would fund dollar holdings ${ }^{10}$. As the cost of funding in pesos increases, banks would try to economize as much as possible in their excess reserves.

A further view at the data raises an issue worth exploring in more detail. During this time, not all banks complied faultlessly with the regulation. Table 4.1 shows the proportion of the 507 observations per bank when excess reserves were negative. The problem that could arise with this situation is that non-compliant banks may report a lower mean for their excess reserves, not because they handle their liquidity position better than the rest, but because they show negative values. To address this issue, we run again the estimation exercise, but this time excluding banks 5,7,13,16 and 17 .

The results that appear in tables 6 and 7 do not alter the story implied by the estimation including all banks. Perhaps the only aspect that deserves any mentioning would be that the CETES and UMS coefficients show smaller

\footnotetext{
${ }^{10}$ According to Hernandez [5], most banks in the sample reported a long net dollar position during the period of study
} 


\begin{tabular}{|c|c|c|c|}
\hline Coefficient & $\begin{array}{r}\text { Homoscedastic } \\
\text { no autocorrelation }\end{array}$ & $\begin{array}{r}\text { Heteroskedastic } \\
\text { no autocorrelation }\end{array}$ & $\begin{array}{l}\text { Heteroskedastic } \\
\text { autocorrelation }\end{array}$ \\
\hline$\beta_{1}$ & 0.8299 & 0.8164 & 0.7337 \\
\hline s.e. & 0.0065 & 0.0072 & 0.0086 \\
\hline$p$-value & 0.0000 & 0.0000 & 0.0000 \\
\hline$\beta_{2}$ & 0.0465 & -0.0031 & -0.0020 \\
\hline s.e. & 0.0342 & 0.0072 & 0.0099 \\
\hline$p$-value & 0.1744 & 0.6694 & 0.8355 \\
\hline$\beta_{3}$ & 0.0454 & 0.0074 & 0.0137 \\
\hline s.e. & 0.0382 & 0.0085 & 0.0115 \\
\hline$p$-value & 0.2353 & 0.3817 & 0.2327 \\
\hline$\beta_{4}$ & -1.3446 & -0.2304 & -0.2858 \\
\hline s.e. & 2.3936 & 0.6002 & 0.7285 \\
\hline$p$-value & 0.5743 & 0.7011 & 0.6948 \\
\hline$\beta_{5}$ & 0.0860 & 0.0112 & 0.0157 \\
\hline s.e. & 0.0283 & 0.0071 & 0.0094 \\
\hline$p$-value & 0.0024 & 0.1124 & 0.0953 \\
\hline$\beta_{6}$ & -0.0197 & -0.0023 & -0.0034 \\
\hline s.e. & 0.0048 & 0.0012 & 0.0016 \\
\hline$p$-value & 0.0000 & 0.0559 & 0.0345 \\
\hline$\beta_{7}$ & -0.0851 & -0.2839 & -0.4147 \\
\hline s.e. & 0.0343 & 0.0330 & 0.0409 \\
\hline$p$-value & 0.0131 & 0.0000 & 0.0000 \\
\hline constant & 0.2536 & 0.3020 & 0.4461 \\
\hline s.e. & 0.0723 & 0.0368 & 0.0462 \\
\hline$p$-value & 0.0005 & 0.0000 & 0.0000 \\
\hline $\mathrm{N}$ & 7097 & 7097 & 7097 \\
\hline \# coefficients & 8 & 8 & 8 \\
\hline \# covariances & 1 & 14 & 14 \\
\hline \# autocorr. & 0 & 0 & 1 \\
\hline Log-likelihood & -10437.5 & -4646.8 & -5022.9 \\
\hline$\chi^{2}$ & 17220.8 & 15723.7 & 8975.9 \\
\hline
\end{tabular}

Table 6: FGLS Estimation results. Non-compliant banks excluded

\begin{tabular}{|l|r|r|r|}
\hline Coefficient & $\begin{array}{r}\text { Homoscedastic } \\
\text { no autocorrelation }\end{array}$ & $\begin{array}{r}\text { Heteroskedastic } \\
\text { no autocorrelation }\end{array}$ & $\begin{array}{r}\text { Heteroskedastic } \\
\text { autocorrelation }\end{array}$ \\
\hline$\widehat{\chi^{2}}$ & 0.0010 & 1.6569 & 1.8744 \\
$\operatorname{Pr}\left(\chi^{2}\right)>\widehat{\chi^{2}}$ & 0.9744 & 0.1980 & 0.1710 \\
\hline
\end{tabular}

Table 7: FGLS Testing $\beta_{2}=\beta_{3}$. Non-compliant banks excluded 
p-values. However, they remain insignificant for a $5 \%$ significance level, if we stick to Bonferroni's testing criterion.

\subsection{TOBIT estimation}

\subsubsection{Methodological considerations}

In this section we will explicitly consider the fact that for most banks and for most of the time, their excess reserves are bounded at values around zero, but not exactly zero. The consequences, already explained in section 2.2, suggest the application of a TOBIT estimation method as a way to avoid a possible estimation bias.

Before doing so, there are some standing issues that needed to be resolved before and during the estimation itself.

Addressing possible Heteroscedasticity . Although we have mentioned that the results of the previous section are likely to be biased, we should not overlook that there is some indication of possible heteroscedasticity across banks. The precise structure of such situation is not known at this point, however a place to start could be to normalize the data, both dependent and independent variables, using some unbiased estimator of the standard deviation of the error for each bank.

- Step 1. We ran a TOBIT estimation for each bank separately. We decided to set the censoring level for this step at $A=0.1$. The regression model used for each bank was the same as equation (10), with the restriction of $\beta_{2}=\beta_{3}=\beta_{7}=0$.

- Step 2. We used the 19 standard error estimates of the regression to normalize the data, including the dummies, corresponding to each block in the panel.

Defining the point where to censor the data. If a typical sample for any bank looks like figure 4, then we know that censoring too soon would lead to biased estimators, and censoring too late would not only cost in terms of efficiency, but the optimization algorithms would have a hard time finding an optimum, as the likelihood function gets more flat. For that reason we opted for a criterion that would look at censoring points that: 
- Are beyond the point where the value of likelihood function ${ }^{11}$ jumps appreciably from the one it has when evaluated with the FGLS estimates.

- Sacrifice as little information as possible. Preferably, choosing a censoring point where more than half of the observations remain un-censored.

- Step 3. The observations for the independent variable are then censored at different points, until we find those satisfying these two criteria.

Choosing the estimation procedure The final step consist of estimating a model homoscedastic across blocks (since the data has been normalized) which, for the sake of increasing efficiency, would consider a random-effects type of covariance structure.

- Step 4. Model in equation (10) is estimated using the xttobit routine by STATA $\AA$, which assumes expression (14).

$$
\begin{gathered}
E\left(\epsilon_{i, t} \epsilon_{i^{\prime}, t^{\prime}}\right)= \begin{cases}\sigma_{1}^{2}+\sigma_{2}^{2} & i=i^{\prime}, t=t^{\prime} \\
\sigma_{1}^{2} & i=i^{\prime}, t \neq=t^{\prime} \\
0 & \text { otherwise }\end{cases} \\
\theta=1-\frac{\sigma_{2}}{\sqrt{507 \sigma_{1}^{2}+\sigma_{2}^{2}}}
\end{gathered}
$$

- It should be pointed out that, to the extent that the standard errors in Step 1 come from a sample censored at the right place, $\widehat{\sigma_{2}^{2}}$ will in turn take values close to 1 .

\subsubsection{Results}

Table 8 displays the results when we take the sample with all 19 banks included. As expected, there are some aspects that are worth underscoring .

- The first column displays results which still look very similar to the FGLS estimation. We will leave this column only as a reference.

\footnotetext{
${ }^{11}$ Evaluated at the optimum
} 
- The next two columns show a positive coefficient for the dummy for the Mexican banks. This leads to conclude that Mexican banks appear to show the kind of response that we would think of institutions with a less advantageous access to international markets than European and Asian Banks. ${ }^{12}$

- In both cases, the constant is also positive. Its size, of about 0.30 means that even European and Asian subsidiaries place an extra reserves equivalent to 4.7 days of due loans. ${ }^{13}$ In contrast, Mexican banks would show an excess coverage between 6.4 and 7.6 days, depending on which column we look at.

- American banks show, either zero or positive values for the coefficients of their respective dummy. However, as suggested by table 9, in these two cases, $\beta_{3}$ is significantly smaller than the coefficient for Mexican banks. This offers some evidence that American banks behaved in a way consistent with better access to external funding.

- The estimated value for $\sigma_{2}$ is close enough to one, which should give us some comfort with respect to the way in which we conducted the Step 1 in the estimation sequence.

- There is a significant and sizeable random effects component in the total standard error ( $\hat{\theta}$ is around 0.30 ), which suggests that beyond the nationality argument, the funding conditions and decisions are subject to relatively large company-specific shocks.

- Finally, except for the SPREAD macro variable, the other ones become significantly different from zero this time around, for a $5 \%$ significance level. They also display the correct signs.

In synthesis, the European and American banks fare better than the Mexican ones. Also, the market conditions appear now to play an important role in explaining the level and dynamics of the excess reserves.

Tables 10 and 11 correspond to the case where the so called non-compliant banks, are excluded. When we do this, some interesting things happen:

\footnotetext{
${ }^{12}$ The critical $p$-value for simultaneous testing is $0.064 \%$ for $q=8$

${ }^{13}$ If all remaining independent variables are zero, the steady state level of excess reserves would be $\nu=\frac{.33}{(1-0.93)}=4.7$.Now, since the dependent variable is (excess reserves/nextday-due loans), the interpretation of $\nu$ would be a coverage expressed in number of days
} 


\begin{tabular}{|c|c|c|c|}
\hline Coefficient & $\begin{array}{l}\text { Censored for } \\
A_{i, t}<0.30 \widehat{\sigma_{i}}\end{array}$ & $\begin{array}{l}\text { Censored for } \\
A_{i, t}<0.35 \widehat{\sigma_{i}}\end{array}$ & $\begin{array}{l}\text { Censored for } \\
A_{i, t}<0.40 \widehat{\sigma}_{i}\end{array}$ \\
\hline$\beta_{1}$ & 0.9115 & 0.9314 & 0.9300 \\
\hline s.e. & 0.0072 & 0.0071 & 0.0072 \\
\hline$p$-value & 0.0000 & 0.0000 & 0.0000 \\
\hline$\beta_{2}$ & 0.0033 & 0.1252 & 0.2633 \\
\hline s.e. & 0.0086 & 0.0108 & 0.0162 \\
\hline$p$-value & 0.6980 & 0.0000 & 0.0000 \\
\hline$\beta_{3}$ & 0.0070 & 0.0021 & 0.1440 \\
\hline s.e. & 0.0090 & 0.0089 & 0.0114 \\
\hline$p$-value & 0.4353 & 0.8117 & 0.0000 \\
\hline$\beta_{4}$ & 0.7260 & 0.3813 & 0.5209 \\
\hline s.e. & 0.6736 & 0.6814 & 0.6933 \\
\hline$p$-value & 0.2811 & 0.5758 & 0.4525 \\
\hline$\beta_{5}$ & 0.0295 & 0.0338 & 0.0309 \\
\hline s.e. & 0.0071 & 0.0071 & 0.0072 \\
\hline p-value & 0.0000 & 0.0000 & 0.0000 \\
\hline$\beta_{6}$ & -0.0111 & -0.0106 & -0.0106 \\
\hline s.e. & 0.0013 & 0.0013 & 0.0013 \\
\hline$p$-value & 0.0000 & 0.0000 & 0.0000 \\
\hline$\beta_{7}$ & -0.1261 & 0.1847 & 0.0618 \\
\hline s.e. & 0.0090 & 0.0156 & 0.0118 \\
\hline$p$-value & 0.0000 & 0.0000 & 0.0000 \\
\hline constant & 0.4944 & 0.3300 & 0.2708 \\
\hline s.e. & 0.0332 & 0.0307 & 0.0302 \\
\hline$p$-value & 0.0000 & 0.0000 & 0.0000 \\
\hline$\widehat{\sigma_{1}}$ & 0.3149 & 0.7374 & 0.7244 \\
\hline s.e. & 0.0128 & 0.0326 & 0.0338 \\
\hline$p$-value & 0.0000 & 0.0000 & 0.0000 \\
\hline$\widehat{\sigma_{2}}$ & 1.0018 & 1.0150 & 1.0227 \\
\hline s.e. & 0.0104 & 0.0107 & 0.0109 \\
\hline$p$-value & 0.0000 & 0.0000 & 0.0000 \\
\hline $\mathrm{N}$ & 9632 & 9632 & 9632 \\
\hline un-censored observations & 5156 & 5022 & 4888 \\
\hline censored observations & 4476 & 4610 & 4744 \\
\hline Log-likelihood & -8862 & -8731 & -8571 \\
\hline$\theta$ & 0.1 & 0.3 & 0.3 \\
\hline$\chi^{2}$ & 24357.9 & 20106.7 & 21908.8 \\
\hline
\end{tabular}

Table 8: TOBIT Estimation results. No banks excluded

\begin{tabular}{|l|r|r|r|}
\hline Coefficient & $\begin{array}{r}\text { Censored for } \\
A_{i, t}<0.30 \widehat{\sigma_{i}}\end{array}$ & $\begin{array}{r}\text { Censored for } \\
A_{i, t}<0.35 \widehat{\sigma}_{i}\end{array}$ & $\begin{array}{r}\text { Censored for } \\
A_{i, t}<0.40 \widehat{\sigma}_{i}\end{array}$ \\
\hline$\widehat{\chi^{2}}$ & 0.1382 & 108.3767 & 99.1436 \\
$\operatorname{Pr}\left(\chi^{2}\right)>\widehat{\chi^{2}}$ & 0.7101 & 0.0000 & 0.0000 \\
\hline
\end{tabular}

Table 9: FGLS Testing $\beta_{2}=\beta_{3}$. No banks excluded 


\begin{tabular}{|c|c|c|c|}
\hline Coefficient & $\begin{array}{l}\text { Censored for } \\
A_{i, t}<0.33 \widehat{\sigma}_{i}\end{array}$ & $\begin{array}{l}\text { Censored for } \\
A_{i, t}<0.35 \widehat{\sigma_{i}}\end{array}$ & $\begin{array}{l}\text { Censored for } \\
A_{i, t}<0.39 \widehat{\sigma_{i}}\end{array}$ \\
\hline$\beta_{1}$ & 0.8976 & 0.9004 & 0.9014 \\
\hline s.e. & 0.0093 & 0.0089 & 0.0090 \\
\hline$p$-value & 0.0000 & 0.0000 & 0.0000 \\
\hline$\beta_{2}$ & -0.1126 & -0.0436 & -0.0678 \\
\hline s.e. & 0.0142 & 0.0080 & 0.0083 \\
\hline$p$-value & 0.0000 & 0.0000 & 0.0000 \\
\hline$\beta_{3}$ & 0.0296 & 0.0049 & 0.0443 \\
\hline s.e. & 0.0091 & 0.0086 & 0.0091 \\
\hline$p$-value & 0.0011 & 0.5669 & 0.0000 \\
\hline$\beta_{4}$ & 0.3179 & 0.3522 & 0.3074 \\
\hline s.e. & 0.6707 & 0.6702 & 0.6768 \\
\hline$p$-value & 0.6355 & 0.5992 & 0.6497 \\
\hline$\beta_{5}$ & 0.0336 & 0.0330 & 0.0330 \\
\hline s.e. & 0.0067 & 0.0067 & 0.0067 \\
\hline p-value & 0.0000 & 0.0000 & 0.0000 \\
\hline$\beta_{6}$ & -0.0109 & -0.0107 & -0.0107 \\
\hline s.e. & 0.0013 & 0.0013 & 0.0013 \\
\hline$p$-value & 0.0000 & 0.0000 & 0.0000 \\
\hline constant & 0.3432 & 0.3320 & 0.3518 \\
\hline s.e. & 0.0348 & 0.0340 & 0.0358 \\
\hline$p$-value & 0.0000 & 0.0000 & 0.0000 \\
\hline$\widehat{\sigma_{1}}$ & 0.2681 & 0.3043 & 0.3396 \\
\hline s.e. & 0.0167 & 0.0139 & 0.0159 \\
\hline$p$-value & 0.0000 & 0.0000 & 0.0000 \\
\hline$\widehat{\sigma_{2}}$ & 0.9787 & 0.9830 & 0.9875 \\
\hline s.e. & 0.0119 & 0.0120 & 0.0121 \\
\hline$p$-value & 0.0000 & 0.0000 & 0.0000 \\
\hline $\mathrm{N}$ & 7097 & 7097 & 7097 \\
\hline un-censored observations & 3961 & 3918 & 3841 \\
\hline censored observations & 3136 & 3179 & 3256 \\
\hline Log-likelihood & -6777 & -6725 & -6638 \\
\hline$\theta$ & 0.1 & 0.1 & 0.1 \\
\hline$\chi^{2}$ & 11535.7 & 12495.0 & 12537.3 \\
\hline
\end{tabular}

Table 10: TOBIT Estimation results. Non-compliant banks excluded

\begin{tabular}{|l|r|r|r|}
\hline Coefficient & $\begin{array}{r}\text { Censored for } \\
A_{i, t}<0.33 \widehat{\sigma}_{i}\end{array}$ & $\begin{array}{r}\text { Censored for } \\
A_{i, t}<0.35 \widehat{\sigma}_{i}\end{array}$ & $\begin{array}{r}\text { Censored for } \\
A_{i, t}<0.39 \widehat{\sigma}_{i}\end{array}$ \\
\hline$\chi^{2}$ & 72.1658 & 27.6343 & 116.2111 \\
$\operatorname{Pr}\left(\chi^{2}\right)>\widehat{\chi^{2}}$ & 0.0000 & 0.0000 & 0.0000 \\
\hline
\end{tabular}

Table 11: TOBIT Testing $\beta_{2}=\beta_{3}$. Non-compliant banks excluded 
- Notice that the DERIVATIVES variable is not included. The reason is that the non-compliant banks and those who are precluded from operating with derivatives are almost the same. This bring about a situation of near-collinearity with the rest of the dummy variables and the constant term. STATA's (B) MLE algorithm this finds it hard to get a single solution when this variable is included. To solve the problem we decided to run the exercise again setting $\beta_{7}=0$ from the outset.

- The Mexican banks show a small, negative but significant coefficient for their dummy. This result, combined with the fact that the American banks report a coefficient significantly larger than the one of the Mexican banks, would come to mean that for the sub-sample of strong performing banks, the Mexicans fare better than all foreign subsidiaries. 14

- In this exercise $\sigma_{2}$ is just shy off 1 . In addition, the contribution of the random-effects component is far more modest than in the previous case $(\theta$ is around 0.1$)$.

- The macro variables are significant in all cases with the exception of the peso-dollar spread. They also keep the order of magnitude and the sign of the case where all banks were included.

\section{Conclusions}

The title of this paper states the question of whether subsidiaries of foreign banks can contribute to the stability of the forex market in Emerging Economies.

The answer is a qualified yes. When there are weak domestic banks, it seems that subsidiaries of foreign banks have a better access to funding in foreign exchange, specially in times of stress.

However, when compared with strong domestic banks, the evidence suggests that these local entities can do as well or even better than the foreign

\footnotetext{
${ }^{14}$ Bonferroni's criterion for $5 \%$ significance level testing, for simultaneously testing the null hypothesis of each coefficient being equal to zero implies a critical p-value of $0.073 \%$. Now, if we test simultaneously the restriction $\beta_{2}=\beta_{3}$, plus the rest of the coefficients being equal to zero, the critical p-value is $0.085 \%$
} 
subsidiaries.

In that sense, the conclusion of this paper takes us back to a common place: there is no substitute to sound banking. It also implies that local authorities can do better by having well capitalized and supervised local banks than by simply allowing foreign subsidiaries in.

As for the more complex topic on the repercussions of the globalization of banking in the Emerging Economies, there are still some unanswered questions. For instance, what should be the shared role of supervision and support of the different financial authorities involved when subsidiaries of foreign banks become a important players in a local market?; or what would be the the macro and regulatory conditions that should prevail in the forex market if a small country would decide to eliminate allow the operation of branches of foreign banks together with local banks and foreign subsidiaries?. A look at some other countries with experiences that complement the one presented here may offer valuable answers on what I think is a very relevant policy issue.

\section{References}

[1] Richard Abrams and Paulina Beato, The prudential regulation and management of foreign exchange risk, IMF Working Paper 98 \#37 (March, 1998).

[2] Menzie Chinn and Michael Dooley, Financial repression and capital mobility: Why capital flows and covered interest rate differentials fail to measure capital market integration, Monetary and Economic Studies (December, 1997), 81-103.

[3] William Greene, Econometric analysis, Prentice Hall, 2000.

[4] Mustafa Gultekin and Alessandro Penati, Capital controls and international capital market segmentation: The evidence fron the japanese and american stock exchanges, Journal of finance $\mathbf{4 4 4}$ \#4 (September, 1989), 849-869.

[5] Miguel Hernandez, Analisis de la eficacia de la regulacion en moneda extranjera de la banca Mexicana, Master's thesis, Instituto Tecnologico Autonomo de Mexico, 2000. 
[6] Alejandro Reynoso, On the effects of regulation-induced forex market segmentation in small open economies: A simulation model based on the stylized facts of the Mexican experience, mimeo, NBER (2001).

[7] __ Using signal processing tools for regulation analysis and implementation: The case of the reserve requirement rules for the foreign exchange transactions in Mexico, mimeo, NBER (2001). 